1. Koch, P. L. et al. Earth Planet Sci. Lett. 108, 277-287 (1992).

2. Fisher, R. S. \& Stueber, A. M. Wat. Resour. Res. 12, 1061-1068 (1976).

3. Graustein, W. C. \& Armstrong, R. L. Science 219, 289-292 (1983).

4. Åberg, G., Jacks, G. \& Hamilton, P. J. J. Hydrol. 109, 65-78 (1989).

5. Miller, E. K., Blum, J. D. \& Friedland, A. J. Nature 362, 438-441 (1993).

6. Bailey, S. W., Hornbeck, J. W., Driscoll, C. T. \& Gaudette, H. E. Wat. Resour. Res. 32, 707-719 (1996)

7. Simkiss, K. in The Ageing of Fish (ed. Bagenal, T. B.) 1-12 (Unwin, Old Woking, 1974).

8. Graustein, W. C. in Stable Isotopes in Ecological Research (eds Rundel, P. W., Ehleringer, J. R. \& Nagy, K. A.) 491-512 (Springer, New York, 1989).

9. Kalish, J. M. Fish. Bull. US 88, 657-666 (1989).

10. Limburg, K. E. Mar. Ecol. Prog. Ser. 119, 25-35 (1995).

11. Chamberlain, C. P. et al. Oecologia 109, 132-141 (1997).

12. Campana, S. E. \& Neilson, J. D. Can. J. Fish. Aquat. Sci. 42, 1014-1032 (1985)

13. Hodell, D. A., Mueller, P. A., McKenzie, J. A. \& Mead, G. A. Earth Planet. Sci. Lett. 92, 165-178 (1989).

\section{DNA fingerprints from} fingerprints

Forensic scientists regularly generate genetic profiles from old blood stains, seminal stains, vaginal swabs, hair, bone, urine and cigarette butts ${ }^{1-6}$. We show that an individual's genetic profile can now also be generated from swabs taken from objects touched by hands, providing a new tool for crime scene investigations. Our findings also demonstrate the need for caution when handling exhibits and when interpreting results.

We swabbed specific areas of hands and objects with cotton cloth dampened with sterile water, using disposable forceps. We extracted $^{7}$ and quantified (ACES 2.0+ program, Gibco BRL) DNA from these swabs, and typed for a short tandem repeat locus using the polymerase chain reaction ${ }^{7}$. We compared the results with independent typings of blood or buccal samples from participating individuals.

Initial tests showed that we could readily obtain correct genetic profiles from swabs taken directly from the palm of a hand (13 of 13). DNA yields varied from 2 to $150 \mathrm{ng}$ (average $48.6 \mathrm{ng}$ ). Dry hands and those that had been washed recently tended to provide the least DNA.

Swabs of objects handled regularly by specific individuals all provided genetic typings that matched the user. Objects included: leather briefcase handles $(n=3$, mean 75 ng DNA), pens ( $n=3$, mean $1.6 \mathrm{ng})$, a car key $(n=1,1.1 \mathrm{ng})$, a personal locker handle ( $n=1,3.7 \mathrm{ng})$ and telephone handsets $(n=5$, mean $10.3 \mathrm{ng})$. One of the telephone handsets also clearly displayed the genetic profile of a known secondary (minor) user.

Furthermore, a number of pre-cleaned objects held for a relatively short period of time (15 min) including: plastic knife han- dles ( $n=6$, mean 17.8 ng DNA), a mug $(n=1,6.8 \mathrm{ng})$, a glass $(n=1,34 \mathrm{ng})$ as well as new vinyl gloves worn for 20 to $90 \mathrm{~min}$ ( $n=8$, mean $51 \mathrm{ng}$ ) gave the genetic profile of the holder or wearer. We found alleles in addition to those of the wearer in samples from two of the gloves, which could be due to secondary transfer. We also found that swabs of the inside of worn $(1 \mathrm{~min})$ condoms $(n=4)$, where no ejaculation occurred, also provide the wearer's genetic profile (mean 11.2 ng DNA). This is relevant to some sexual offence investigations.

DNA yields from swabs of polypropylene tubes held for varying lengths of time ( $5 \mathrm{~s}, 30 \mathrm{~s}, 3 \mathrm{~min}, 10 \mathrm{~min}$ ), did not differ significantly, indicating that substantial transfer of material occurs during initial contact.

Objects handled by many individuals all produced profiles with multiple alleles of varying intensity. To determine the effect of multiple handlers, we exchanged polypropylene tubes between individuals ( 2 or 3 , $10 \mathrm{~min}$ each) with different genotypes. Although the material left by the last holder was usually present on the tube, that of previous holders was also retrieved to varying extents. The strongest profile obtained was not always that of the person who last held the object, but was dependent on the individual. We regularly observed profiles of previous holders of a tube from swabs of hands involved in these exchanges, showing that in some cases material from which DNA can be retrieved is transferred from object to hand (secondary transfer).

Also, hands swabbed before and after a one-minute handshake revealed the transfer of DNA from one individual to another in one of the four hands tested. Thus genetic profiles from objects handled by several people or from minute blood stains on touched objects may be difficult to interpret.

There are many cases in which the genetic profile of individuals who may have handled or touched particular objects associated with a crime could be extremely important to an investigation. Our methods have already been used at our laboratory to provide evidence in attempted murder, rape, armed robbery, extortion and drugtrafficking cases.

\section{Roland A. H. van Oorschot}

Maxwell K. Jones

Victoria Forensic Science Centre,

Victoria Police, Macleod,

Victoria 3085, Australia

1. van Oorschot, R. A. H., Gutowski, S. J., Robinson, S. L., Hedley, J. A. \& Andrew, I. R. J. Forensic Sci. 41, 142-145 (1996).

2. Higuchi, R., von Beroldingen, C. H., Sensabaugh, G. F. \& Erlich, H. A. Nature 332, 543-546 (1988).

3. Hagelberg, E., Sykes, B. \& Hedges, R. Nature 342, 485 (1989).

4. Hagelberg, E., Gray, I. C. \& Jeffreys, A. J. Nature 352, 427-429 (1991)

5. Brinkman, B., Rand, S. \& Bajanowski, T. Int. J. Legal Med. 105, 59-61 (1992).

6. Hochmeister, M. N. et al. Int. J. Legal Med. 104, 229-233 (1991). 7. van Oorschot, R. A. H., Gutowski, S. J. \& Robinson S. L. Int. J. Legal Med. 107, 121-126 (1994).

\section{How many replicons make a nodule?}

Allan Downie, in his commendable News and Views discussion ${ }^{1}$ of our work ${ }^{2}$, suggests that a second, non-chromosomal symbiotic replicon could be present in the bacterial Rhizobium species NGR234. So far, our asyet unpublished work on physical mapping and random sequencing of the NGR234 genome by V. Viprey, C. Freiberg and X. P. has produced no evidence of another plasmid. Further, the electrophoretic methods we used could visualize the twin symbiotic plasmids (relative molecular mass $\left(M_{\mathrm{r}}\right)$ $1 \times 10^{9}$ ) of $R$. meliloti, but in the event consistently demonstrated only a single plasmid of $M_{\mathrm{r}} 3.1 \times 10^{8} \pm 2 \times 10^{7}$ in NGR234 (refs 3, 4). Thus, although Morrison et al..$^{5}$ reported that NGR234 contains two plasmids of $M_{\mathrm{r}}$ $3 \times 10^{8}$ and $4.5 \times 10^{8}$, it seems unlikely that a second plasmid exists. It is true, however, that some nodulation and other symbiotic genes map to the chromosome ${ }^{6}$. (Incidentally, the fixABC cluster is present on pNGR234a.)

\section{Xavier Perret, William Broughton}

LBMPS, Université de Genève,

1 chemin de l'Impératrice,

1292 Chambésy/Genève, Switzerland

e-mail:broughtw@sc2a.unige.ch

1. Downie, A. Nature 387, 352-354 (1997).

2. Freiberg, C. et al. Nature 387, 394-401 (1997).

3. Broughton, W. J., Heycke, N., Meyer z. A., H. \& Pankhurst, C. E. Proc. Natl Acad. Sci. USA 81, 3093-3097 (1984).

4. Broughton, W. J. et al. Arch. Microbiol. 141, 14-21 (1985).

5. Morrison, N. A. et al. J. Bacteriol. 160, 483-487 (1984).

6. Perret, X., Broughton, W. J. \& Brenner, S. Proc. Natl Acad. Sci. USA 88, 1923-1927 (1991).

\section{Unique morphology of the human eye}

Human eyes have a widely exposed white sclera surrounding the darker coloured iris, making it easy to discern the direction in which they are looking ${ }^{1}$. We compared the external morphology of primate eyes in nearly half of all primate species, and show that this feature is uniquely human. Humans have the largest ratio of exposed sclera in the eye outline, which itself is elongated horizontally. We suggest that these are adaptations to extend the visual field by allowing greater eye movement, especially in the horizontal direction, and to enhance the ease of detecting the gaze direction of another individual.

We measured three parameters in 88 primate species: an index of exposed sclera size (SSI) in the eye outline, the width-height ratio (WHR) of the eye outline and the sclera coloration. Human eyes have the largest 
SSI and the outline shows extraordinary horizontal elongation. Humans are also the only species with white sclera. We failed to detect any significant sexual or racial differences in these parameters. Although a small number of primates had pale sclera (Macaca sylvanus, M. nemestrina) or brown sclera with small white regions to the side of the iris (Saguinus midas, S. labiatus, Callithrix argentata, Callimico goeldii), almost all other primates examined have similar coloration to that of the skin around the eyes (Fig. 1).

SSI correlates with weight and crownrump length ${ }^{2,3}(r=0.59, P<0.001$ in both cases), sitting height $(r=0.65, P<0.001)$ and walking height $(r=0.71, P<0.001)$ (Fig. 2). Larger SSIs allow the iris a wider range of movement and hence a larger visual field. This may be advantageous to larger species where eye movement becomes increasingly more efficient than head or body movement, especially as comparative eyeball size is smaller in larger animals. In addition, in small species with comparatively large eyeballs in a small skull, muscle space may be seriously limited.

We video-recorded various primates eating (18 species, 29 individuals), and counted eye and head movements. The amount of scanning by eye movement alone was correlated with SSI $(r=0.73, P<0.005)$ and was high in humans $(61 \pm 28 \%$ of horizontal scanning, $n=5$ ) compared with other primates (4.3-24.4\%; mean, $10.6 \%$ ). The highest rate in non-human primates was observed in the chimpanzee, Pan troglodytes $(20-35 \%, n=3)$.

WHR is largest in terrestrial species, smallest in arboreal species, with semi-arboreal species lying in-between (Fig. 1). There is a corresponding high ratio of horizontal to vertical scanning in terrestrial species, as might be expected to suit this lifestyle, and a low ratio in arboreal species. The ratio is correlated with WHR (scanning time ratio: $r=0.74, P<0.001$; frequency ratio: $r=0.88$, $P<0.001)$.

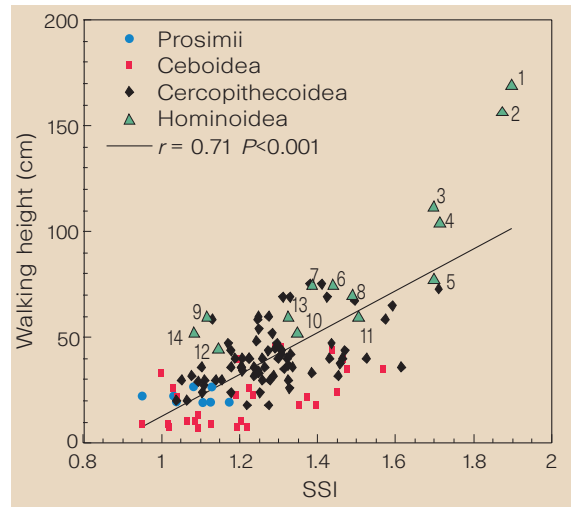

Figure 2 Relationship between SSI and walking height. 1, Human (Japanese) male; 2, female; 3, G. gorilla male; 4, female; 5 , P. pygmaeus female; 6 Pan troglodytes male; 7, female; 8, P. paniscus male; 9, H. agilis female; $10, H$. lar male; 11 , female; $12, H$. pileatus female; 13, H. syndactylus male; 14 , female.

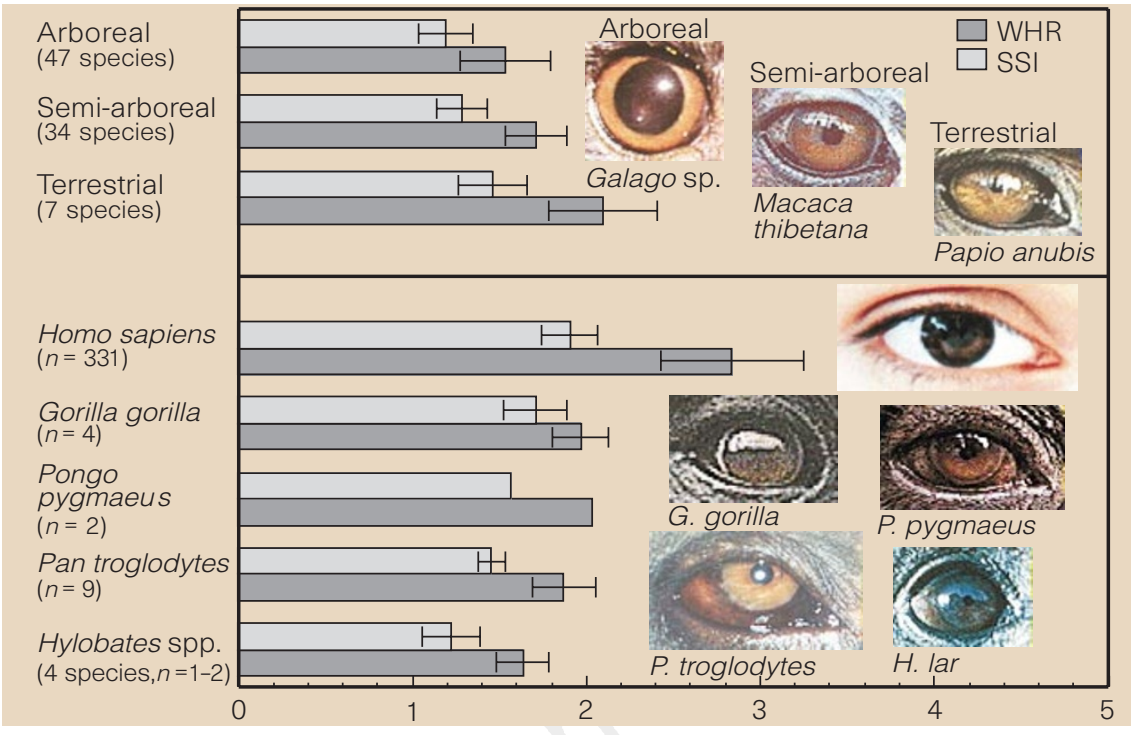

Figure 1 Variation of WHR and SSI (mean \pm s.d.). Difference between habitat types was significant (WHR: $F_{2,85}=18.69, P<0.01$, least significant difference, mean square of errors $=0.058, P<0.01 ; \mathrm{SSI}: F_{2,85}=10.86$, $P<0.01$, least significant difference, mean square of errors $=0.024, P<0.01$ ). We studied frontal full-face images without obvious facial expression of 387 adult animals (88 species: Prosimii, 10; Ceboidea, 26; Cercopithecoidea, 43; Hominoidea, 9). Facial images of 80 species were recorded by video camera at the Japan Monkey Centre and those of 8 species (Microcebus sp., Loris tardigradus, Perodicticus potto, Tarsius sp., Saguinus imperator, Pithecia monachus, Cacajao rubicundus, Cercopithecus hamlyni) were collected from books. 182 Japanese, 80 Caucasian ${ }^{8}$ and 68 Afro-Caribbean ${ }^{8,9}$ adults were observed. Images were analysed using the $\mathrm{NIH}$ Image program. WHR = distance between the corners of the eye/longest perpendicular line between the upper and lower eyelid; SSI = width of exposed eyeball/diameter of iris.

Microscopic analysis of Japanese macaque (Macaca fuscata) eyes showed brown pigmentation of the sclera tissue around the cornea, apparently common in primates and other mammals. This pigmentation was thought to reduce glare as it is absent in many nocturnal and crepuscular species ${ }^{5}$, but nocturnal primates (Gelago senegalensis, Tarsius syrichta, Perodicticus potto, Nycticebus coucang and Aotus trivirgatus) also had coloured sclera and diurnal humans showed no pigmentation.

In many primates, gaze direction is important in communication, and direct eye contact often elicits attacks. Sclera pigmentation to obscure the gaze direction may thus be adaptive ${ }^{6}$. It may also serve to deceive natural predators, as if the predator believes that the prey animal is aware of its presence, it may be less likely to attack ${ }^{7}$. In some nonhuman primates ( 9 of 10 species examined), sclera coloration of newborns was paler than adults, indicating that infant gaze signals might have special meanings in these species. In all of 14 species examined, including humans, SSI and WHR of newborns were lower than those of adults.

The human sclera is much paler than the facial skin or iris so it is very easy to discern the gaze direction. Predation risk might have decreased with the evolution of enlarged body size and the use of tools and fire. In addition, gaze-signal enhancement might aid the communication required for increased cooperative and mutualistic behaviours to allow group hunting and scavenging. A small change in sclera coloration may have altered 'gaze-camouflaged' to 'gaze-signalling' eyes. SSI and WHR of human eyes are even larger than those of gorillas, the largest primate, which suggests adaptation for gaze-signal enhancement. The uniqueness of human eye morphology among primates illustrates the difference between humans and other primates in the ability to communicate using gaze signals.

Hiromi Kobayashi, Shiro Kohshima

Basic Biology, Faculty of Bioscience and

Biotechnology (clo Faculty of Science),

Tokyo Institute of Technology, 12-1,

O-okayama 2-chome,Meguro-ku, Tokyo 152, Japan e-mail:hiromi@chem.titech.ac.jp

1. Morris, D. Body Watching (Equinox, Oxford, 1985).

2. Itani, J. \& Uehara, S. The Encyclopaedia of Animals (ed. Macdonald, D. W.) (Heibonsha, Tokyo, 1986).

3. Napier, J. R. \& Napier, P. H. The Natural History of the Primates (MIT Press, Cambridge, MA, 1985).

4. Schultz, A. H. Am. J. Phys. Anthropol. Old Ser. 26, 389-408 (1940).

5. Duke-Elder, S. S. in System of Ophthalmology (ed. Duke-Elder, S. S.) 453 (Kimpton, London, 1958).

6. Perrett, D. I. \& Mistlin, A. J. in Comparative Perception -

Complex Signals (eds Stebbins, W. C. \& Berkley, M. A.) $187-215$ (Wiley, New York, 1990).

7. Sherman, P. W. Science 197, 1246-1253 (1977).

8. Ohara, K. ONE (Tsukui Shokan, Tokyo, 1970).

9. Gomi, A. Americans 1.0 1994 Los Angels (Fuga Shobo, Tokyo, 1994).

\section{erratum}

In the Scientific Correspondence "Evidence for stone age cranial surgery" by Kurt W. Alt et al. (Nature 387, 360; 1997), the carbon-14 estimate of the age of the human bones was printed incorrectly. It should have read "Utrecht ${ }^{4} \mathrm{C}$ laboratory sample UtC-5406: 6,155 \pm 39 radiocarbon years before present, $\sim 5100$ BC'. 